\title{
On Knowledge and Law: The Role of Law in the Generation and Harmonisation of Knowledge
}

\begin{abstract}
The relation of law and knowledge is not a well-developed field of legal theory and legal research. This might be a legacy of the methodological approach of German legal theory, which leaves little room for a shift to perceive law as a knowledge generating procedure. The application of law is based on shared conventions and meanings, which give a semblance of stability. This semblance erodes in dynamic environments. In such situations, instead of drawing on consolidated knowledge, the law establishes and frames knowledge generating procedures and infrastructures to secure the necessary knowledge, e. g. for regulation. This also applies to Europeanisation and internationalisation of law. Law itself often institutionalises a kind of reflexive and learning structure in order to assure its common application. At the end of my essay, a short outline of changes in knowledge generating procedures through digitisation is given.
\end{abstract}

Zusammenfassung: Das Verhältnis von Recht und Wissen ist kein gut entwickeltes Gebiet der Rechtstheorie und Rechtswissenschaft. Dies könnte ein Vermächtnis des methodischen Ansatzes der deutschen Rechtstheorie sein, der wenig Raum für einen Wechsel zur Analyse des Rechts als wissenserzeugendes Verfahren lässt. Die Anwendung des Rechts basiert auf gemeinsamen Konventionen und Bedeutungen, die einen Anschein von Stabilität vermitteln. Dieser Anschein erodiert in dynamischen Umgebungen. Anstatt auf das Alltagswissen zurückzugreifen, schafft und rahmt das Gesetz in solchen Situationen wissensgenerierende Verfahren und Infrastrukturen, um das notwendige Wissen zu sichern, beispielsweise für die Regulierung. Gleiches gilt für die Europäisierung und Internationalisierung des Rechts. Eine Art reflexive und lernende Struktur wird oftmals durch das Gesetz selbst institutionalisiert, um die gemeinsame Anwendung zu gewährleisten. Zum Abschluss meines Beitrags wird ein kurzer Abriss von Veränderungen durch den Digitalisierungsprozess im Recht mit Blick auf Wissen gegeben.

\section{Introduction}

Although there is a growing literature on the topic of law and knowledge, ${ }^{1}$ one must admit that this is not a well-developed field of legal theory and legal research - at

1 See Albers 2008; Augsberg 2014; Broemel 2010b and 2013; Fassbender 2006; Herzmann 2010; Ladeur 1995 and 2016; Oeter 2011; Reiling 2016; Stegmaier 2009; Trute 2010 and 2016; Voßkuhle 2008; Wollenschläger 2009.

əOpen Access (C) 2020 Competing Knowledges - Wissen im Widerstreit, ed. by A. M. Horatschek (Abhandlungen der Akademie der Wissenschaften in Hamburg 9), De Gruyter. [ख) Br-Nc-ND Dieses Werk ist lizenziert unter der Creative Commons Attribution-NonCommercial-NoDerivatives 4.0 Lizenz. https://doi/10.1515/9783110659658-006 
least in the German discourse. Law is seldom seen as a knowledge-generating practice. It seems to be a truism that every legal decision and every legal communication contributes to the stock of knowledge about the law itself. In addition, the process of applying the law is also a source of knowledge about the issues that the law deals with. Decisions not only tell something about the micro practices in question in a particular case, but also give information about the structures, habits and problems of respective fields. More important is the role law plays in the generation of knowledge by framing the processes of knowledge production and distribution. Obviously, law plays a significant role in the production and distribution of knowledge, although this role is not researched systematically.

I assume that this is a legacy of the methodological approach of German legal theory. I shall start my paper by developing this hypothesis and outline the classical model of jurisprudence, which leaves, at least to my mind, little room for a shift to perceive the application of law as a knowledge generating practise. Such an approach will be developed in part three of this paper. I will argue that the application of law is based on shared conventions and meanings, which give a semblance of clarity and stability responsible for simple models of application. In part four I will show that in dynamic environments this clarity and stability, which are grounded in knowledge from everyday experience, vanish. Thus, Europeanisation and internationalisation challenge the shared conventions and meanings, due to the diversity of legal cultures. Instead of drawing on everyday practice, the law establishes and frames knowledge generating procedures and infrastructures to secure the necessary knowledge, e. $\mathrm{g}$. for regulation. In this way, a kind of reflexive and learning structure is often institutionalised by law itself to assure its common application. This harmonisation of varying legal knowledge formations by framing a common practice is analysed in part five. The final chapter six will offer a short outline of digitisation in law, which will probably change the processes of knowledge generation much faster than envisaged.

\section{No Place for Knowledge: The Classical Model of Jurisprudence}

I shall at first outline the classical model of jurisprudence in order to answer the question why knowledge production is not a central topic in legal research.

\subsection{The Doctrinal Approach}

The following explications will sketch what might be called the doctrinal approach in applying law (for an overview and a fierce justification of the doctrinal method see Smits 2017). It will be shown that there is not a well-defined place for knowledge 
and knowledge orders within this so-called "classical” approach. In the realm of legal science (jurisprudence) - at least from the perspective of civil law, ${ }^{2}$ which is traditionally very influential for legal theory in Germany -, law is all about interpretation of texts (norms) and applying rules (texts) to facts, which implies the subsumption of facts under the law. The use of a more or less prescribed canon of interpretation methods is supposed to adequately unfold the meaning contained in the text of law. In a next step, it is a matter of checking the facts to see whether they can be subsumed under the rule obtained in this way by interpretation. If this is attained, a concrete legal consequence can be attributed to a norm with regard to a particular case (cf. the canonical textbook of Canaris/Larenz 2001). Although only possible in a simplified manner, I consider it useful to describe in nuce this classical model of jurisprudence (for a critical overview see Rübben 2015: 19-73).

\subsection{The Meaning of Texts as a Blind Spot}

From a methodological point of view, positivists follow a recognition model of law (Christensen 1989): The meaning of the law can be recognized. Even though there have been very different forms and varied theories of the application of law, these classical (positivist) variants have in common that laws are understood as the legislator's expressions of will, which can be recognised and semantically deciphered. The existence of a meaning inscribed in the text of the law is the core assumption of the model (for a critical summary see Somek 2006: 53-92). Often this assumption is justified with reference to the principle of democracy, because the parliament, legitimised by the people, enshrines the meaning in the text only to be unfolded by those applying the law. Either the meaning is more or less clear from the beginning, or various methodological tools have to be used to determine the meaning of texts, in particular if some indeterminacy is to be observed. In this case, as is often said, the original will of the lawmaker has to be discovered by analysis of secondary texts like materials of the process of law-making. From different disciplinary angles, in particular from a linguistic perspective, of course it appears questionable that the meaning of a text can be determined with reference to an author intention, and that the text itself preempts its application (Christensen 1989). In this respect, meaning is the blind spot of the entire application problem. I will not tackle the various attempts to cope with the fallacies of this approach but only note that up to today this model is advocated by courts and practitioners of law, if they reflect their work: There is a fixed meaning of the text (given as norms), which can be deciphered with specific tools of interpretation. This approach can be characterised as an internal procedure of knowledge pro-

2 An analysis of the nineteenth-century methodological thinking can be found by Ogorek 2011, revising a monolithic narrative about the formalistic approach of the nineteenth-century discussion in German legal theory. 
duction, as the legal system is not only the subject of the inquiry, but also provides the normative framework for analysis. The discourse that results from these premises does not need anything outside of the law to be carried out (Smits 2017). This goes hand in hand with the role ascribed to legal researchers, which likens them to judges. ${ }^{3}$ As a result the distinction between decision-making as application of law and observing decision-making in law collapses and both discourses are supposed to speak the same professional language. Moreover, the doctrinal approach understands law not as a system of communication, but of coherent assertions about legal texts, norms etc. The approach is seen as giving more than a mere description of existing legislation and case law, as it requires the organisation and re-organisation of coherent principles, rules and concepts before one can speak of a doctrine (ibid.). This systematisation is related to the current law, not to the history or politics of law. It is therefore not surprising that the questions of whether it is at all possible to guarantee a uniform understanding of law through texts, how such an understanding can possibly be achieved, whether a common and shared knowledge of law is required in any case, why there is such a thing as a uniform understanding of law at all and how it is institutionalised cannot be answered within the framework of this approach, because they are considered as external questions that can be left to other sciences.

\subsection{Facts as a Given}

The same is true for the other side of the distinction between text and fact, namely the facts. Facts are often seen more or less as a given, provided by the parties, controversial questions being decided upon by rules of evidence (again with the help of an interpretational approach). If necessary, the interpretation will be provided or at least evaluated by experts of a professional field, or by scientific experts. Again, this procedure is governed by rules, but the consequences are seldom spelled out in detail and methodological concerns like the constructive character of the case or the transformation of a social event into a legally constructed case are rarely reflected in the model. This transformation is accountable for the fact that the parties to a case as well as external observers of the legal system and its procedures often experience a kind of alienation when confronted with the legal description of "facts". ${ }^{4}$ However, within

3 Smits (2017: 222-227) assigned them profoundly different tasks along the line of deciding concrete cases and developing the system, although they use the same language. Note the interesting bias that Smits does not refer to administrators, which obviously do not fit the model. Assuming that administration primarily implements politics (Niklas Luhmann) but can of course be legally assessed in doing it, the question arises as to how this can be described.

4 For this passage and transformation, see Harenburg/Seeliger 1979; Rosen 2006: 68-70: "Legal Systems create facts in order to treat them as facts. Even when there is little dispute over what 'really' happened, something must first be regarded as a fact if it is to count as such. [...] Whether skelatized or fleshed out, a society's legal process will, then, by its way of creating categories of the knowable 
the classical approach, there is little reflection about the fact that a specific kind of legally framed and shaped knowledge is produced when processing the law.

\section{A Shift to a Knowledge Generating Perspective}

Meanwhile, due to developments in linguistics, the philosophy of language, pragmatism and ethno-methodological theories, central assumptions of the classical model, like the text as a transparent medium of transmission for the author's intention (lawmaker) to those applying the law, have been refuted - with a variety of consequences.

\subsection{Communities of Practice}

Despite significant differences, some aspects of non-classical approaches can be sketched out as a kind of common ground. If one understands the text as a transitory area of various interpretations (Müller/Christensen/Sokolowski 1997), there seems to be a flipside of this approach: the problem of decisionism and arbitrariness. This concern has alerted legal theory to look for constraints to arbitrary interpretations (Fish 1989). Answers have been sought in different ways, post-Wittgenstein positions, structuring legal theory (Müller/Christensen 2004), post-positivist theories (Somek 2006) and constructivist positions (Lee 2010; Stegmaier 2009). As I am interested in the place of knowledge in legal methodology, not in participation in the ramified discussion of methods, for my topic only the stance on knowledge is important. What these positions have in common is their focus on the application of law as a process of the production of legal knowledge, on interpretative communities (Fish 1989), on experimental, always provisional attributions of meaning resulting from a large number of decisions (Busse 1993), on habits of language communities (Somek 2011) and on constructivist positions, which - more significant for our purposes - deal with how the knowledge of law is produced through the practice of interpretative communities. Despite the differences in detail, these positions in toto allow a view of the (social) prerequisites for the practice of applying norms, which can be understood as the generation of a common, albeit always preliminary, knowledge.

and relating them to the ways in which facts are constructed in the culture at large"; Vogel/Hamann/ Gauer 2018 referring to legal language as a medium to transform nonlegal subjects into legal things, argumentation and working procedures. 


\subsection{A Reflexive Structure of Knowledge Production}

With this background, one can reconstruct how the legal system of meanings, understood as the entirety of that knowledge, is produced, concretised and constantly confirmed and varied in communicative procedures (Lee 2010: 47, 84 et seqq.). Every single legal communication is based on the body of knowledge and as such is identifiable as a legal communication against the background of this knowledge. By the same act this knowledge is confirmed or varied - a kind of recursive structure with dynamic interrelations between social structures, legal meanings (i. e. the structural level) and individual communications.

This perspective allows for an analysis of the professional legal work both in terms of the evolution and the differentiation of commonly shared knowledge of lawyers, as well as the micro practice of reconstructing concrete decision capabilities. Such an approach shifts the focus from singular textual analysis to the analysis of legal practice and its constraints. It makes it possible to determine more precisely the function of legal dogmatics, of legal principles and precedents, of lines of case law of the respective courts and of explicit as well as implicit knowledge every legal professional has to acquire for stabilisation and use (Lee 2010: 152 et seqq.). It also permits one to pick up the legal communication in its profoundly different facets and allows raising the question of how this knowledge is generated, acquired, stabilised and distributed within the legal system.

\subsection{Between Continuity and Variation}

Of course, what has been described here as a pool of knowledge is enormously differentiated and ultimately disparate from the perspective of the individual legal professional. The national legal system, based on a more or less harmonised framework of legal education, has developed means to cope with the complexity and heterogeneity of the knowledge base. Thus, a complex system like this needs a developed publication system for different needs: redundancy and variation, report and analysis, theory and practice, decision-oriented and systematic, general and specialised, to mention just a few criteria to differentiate the respective journals. Textbooks would be another genre, for example monographs or commentaries, the latter being of enormous importance, epitomising the context and thus serving as a means of continuity and orientation (Kästle-Lamparter 2016). All of these texts contribute to the conventionalisation of meaning, as well as being a source of alternatives.

A little researched area is the function of the court system with respect to knowledge generation. This is partly a consequence of the legal recognition model, which conceptualises disparate solutions of a case or a problem in different courts as an assembly of errors, which can be corrected in the course of instances. However, from a knowledge generating perspective, the system of legal instances functions as a tool 
for harmonisation and conventionalisation as well as variation - again on a preliminary basis. Due to the fragmentation of the court system and the sheer number of courts, the system leaves room for variation and evolution and thus again raises the question of how exactly continuity is achieved. In the following, I shall outline some aspects of this question.

It seems to me that, although in the German system in most cases there is no binding nature of precedents and no formal hierarchy except in dealing with the same case, the position of the court in the court system as well as its reputation play an important role. Another question might be, how each court, chamber and senate manages continuity, although there will always be a change of members. Two aspects seem worth mentioning: The first is what might be called lines of court decisions, which refer to the fact that every decision-making body has some internal yardsticks, established by former decisions of the decision-making body as well as other decisionmaking bodies like courts of higher instance (Stegmaier 2009: 280 et seq.; for further streamlining mechanism assuring continuity, see 307 et seq). These considerations are a means of continuity that is often underestimated. The second tool is the recourse to text modules to reach a decision. Often the formulated text will contain a section, where text modules define the abstract measures of the case, or where precedents are displayed to unfold a body of common knowledge related to questions at stake. These modules not only represent the internal decision lines, ${ }^{5}$ but also will often find their way into textbooks and commentaries, introductions for students and trainees, and into journals' summaries of decisions. In this way, they represent an important contribution to and an aspect of continuity for common measures of decision-making, as they explicate a common knowledge of legal professionals within the respective field.

Other sources of knowledge generation are the parties to a case, the legal professionals publishing in professional journals, the courts by giving reasons for their decisions and the administration in deciding cases and performing public hearings. All of them contribute to the legal discourse. This discourse about the law is public and performed through the media and thus is a driving force for legal knowledge production as well; these practices have the capacity to shift the meaning of law, and they are used by societal actors to strategically influence the law via a public discourse. All of these strategies form a reflexive process of production of knowledge by taking the existing knowledge formation as a starting point and confirming or modifying it in the process of using it: the recursive logic of knowledge production by and of the law.

5 This is why we will find chains of citations of former decisions of the respective courts which signal continuity, or - in more case law oriented systems like the practice of the European Court of Human Rights - a summary and discussion of the court's case law in the respective field. 


\title{
3.4 Law as a Knowledge Generating Practice
}

This analytical shift to a knowledge generating perspective is, of course, influenced by the sociology-of-knowledge approach. Our Canadian colleague Marianna Valverde emphasises this shift in her seminal book on Law's Dream of a Common Knowledge (2009: 5-6; italics in the original):

\begin{abstract}
But what if we decide to take an interest in the workings of law not in order to move it closer to justice or to make it more rational or both but, less normatively, in order to study the mechanisms by which law, rather than simply using facts in the form of "evidence," also produces knowledge? [...] The [...] sociology-of-knowledge analysis can be applied to law; that is, the parties to a legal case can be said to constitute knowledge in the very process of "using" it, while courts and tribunals can be usefully regarded as further constituting knowledge in the process of evaluating evidence and drawing conclusions from it. "Construction," or the term I prefer (in part because of its rich legal connotations), "constitution," refers to the processes that grasp some bit of the world in accordance with existing cultural codes and thus make it meaningful for a particular group. [...] Similarly, legal facts and legal judgments are only meaningful and effective within a network, one that connects legal decisions and statutes but also includes buildings (e. g., prisons), clothes (robes, uniforms), information codes, individuals, institutions such as legislatures, law schools, and courts, professional associations, and extralegally produced texts such as psychological reports, police notes, and scene-of-crime photographs.
\end{abstract}

This quote best summarises the agenda of the shift, opting for the departure from a merely textual doctrinal approach and for the study of law as a knowledge generating practice.

\section{Discontinuity in Dynamic Environments}

According to the theses developed in the frame of a sociology-of-knowledge approach, law is based on shared knowledge and conventions. In this model, the text does not allow only one interpretation of the supposed author intention and thus imply one determined. Instead, any reading remains an interpretation that could vary according to circumstances and developments.

We follow the hypothesis that the law is stable as long as the law is based on shared knowledge and conventions. This results in the assumption of a stable and commonly shared meaning of the law, on which more traditional methodological positions base their approach (for a critique see Fish 2011). If these conventions are undermined with regard to their normativity or their factual side, the seeming objectivity of meaning disintegrates. In this situation, the commonly shared knowledge does not provide a sufficient solution; instead new knowledge is generated and has to be stabilised. 


\subsection{The Semblance of Clarity: Conventions and Knowledge from Everyday Experience}

For a long time public law and in particular administrative law seemed to be relatively stable, based on a commonly shared perspective among professionals. ${ }^{6}$ In many cases, a specific part of generally accessible knowledge can be developed within a legal system through commonly available facts, complemented by a wide variety of cases or through common knowledge based on experience. Eventual changes occur slowly and, therefore, the impression of a more or less self-evident reality and unquestionable (more or less tacit) knowledge, on which the application of law can be based, is maintained. One example is the notion of 'danger', which is the central notion of the so-called police law, which aims at regulating everyday social order to avoid harm for citizens, institutions and the environment, and which in cases of a manifest disruption is expected to maintain or remediate the social order. According to the texts, which have been relatively stable for more than a century, the administrative authorities shall take such measures as may be necessary to protect the public or the individual in order to avert imminent dangers to public security and order, or to eliminate disturbances to public security and order. This is a very general clause, concretised by the courts through a wide variety of cases. According to the courts, a danger is imminent when damaging conditions are likely to arise from actual conditions under the law of causality. ${ }^{7}$ The Prussian Higher Administrative Court held that this notion of danger is based on the experiences of everyday life. ${ }^{8}$ Thus it appears easy to handle, although it has to be applied to a wide range of different situations. As long as this concept can be assessed with reference to knowledge, stemming from daily experience, the application of law runs smoothly. Even in cases where more specialised knowledge is needed due to the risks at hand, it is applicable, albeit with the help of experts. ${ }^{9}$ Irrespective of the increasing recourse to expert knowledge as a result of technological developments, the concept implies a deterministic model in which past and future are causally and stably linked (Wollenschläger 2009: 12 et seq.). In such cases, knowledge about the law and its application is generated through the process of application. This allows legal simplifications, which methodically evolve into simple constructions of subsuming facts under norms with regard to their significance.

\footnotetext{
6 There is an often cited phrase from Otto Mayer, the famous conceptualist of Administrative Law who wrote after the revolution in 1918 in a preface to the new edition of this seminal textbook on administrative law: "Great news has never happened. Constitutional law passed away, administrative law still remains". It illuminates the stability of some areas of law, no matter what happened, as long as the context did not affect the process of application of law.

7 PrOVG, PrVBl 16 (1894), 125 (126).

8 PrOVG, RVBl 1931, 330.

9 PrOVG, PrVBl 16 (1894), 125 (126).
} 


\subsection{Dynamic Environments}

The impression of continuity vanishes in dynamic situations. Environmental law is a good example of the fact that the general basis of legal knowledge erodes the moment everyday and expert knowledge are insufficient to access the situation, and the application of general principles as illustrated here with the example of police law no longer works. The development of the precautionary principle, which extends the possibility of state intervention in situations of uncertainty, is a good example for the erosion of the knowledge base. Recognition of uncertainty is a fundamental problem of law, which leads to new forms and legal dogmatics because the strategies exemplified in police law no longer allow for adequate results. A lack of scientifically generated knowledge, unclear causal relations and considerable damage potentials, the occurrence of which is not foreseeable yet demand preventive action, are responsible for the insufficiency of the old model. A long debate on an international scale about an adequate understanding of precautionary measures bears eloquent witness to the fact that the horizon of commonly shared knowledge has eroded. The procedures of police law with the basic category of hazards are retained for manageable situations, but in the long run cannot assume the regulation of complex environmental problems.

This development can be generalised: if the law refers to complex and dynamic environments, such as market regulation, financial risk regulation, technological risks and health regulations, to mention just a few examples, no one can rely on the inventory of knowledge based on everyday experience. With reference to the norms, this lack of knowledge manifests as vagueness and ambiguity. With regard to the factual side, it is not certain that the information necessary for taking decisions in the respective field is available in time. Usually, such a situation leads to open standards, but also to unique procedures for generating indispensable practical knowledge. It is not easy to mark a clear-cut differentiation between norms and facts in this situation. Rather, open rules and undetermined notions are concretised, thus preparing knowledge and an enriched understanding of the situational aspects of open legal norms. Knowledge generation is thus an issue beyond mere clarification of facts, but involves the production of measures for a decision according to the situation. In this sense, one may speak of knowledge generating procedures, which need to be established (Wollenschläger 2009: 24 et seq.). The more dynamic an environment, the more decentralised is the generation or distribution of knowledge, and the more open the normative standards, the more dependent are necessary norms on processes of knowledge generation (Röhl 2012).

One of the regulatory options is to rely on open procedures, public hearings and other forms of public discourse in order to generate conventions, at least for a certain period of time. Alternatively, processes specifically designed to generate knowledge are created. 


\subsubsection{Knowledge Generating Procedures}

In many areas of regulation, it cannot be expected that the science system will provide the regulatory knowledge within its normal operations, which could be transformed into a legal decision-making context via rules of evidence and by experts. As the fairly complex system of legal decision-making cannot rely on a kind of randomised knowledge production of the scientific system, knowledge generating procedures are established, which are configured by law itself.

First of all, knowledge is for a large part partially (co-)constructed normatively when it concerns regulatory and risk decisions. The legal order poses detailed topics, questions and, to a certain degree, also methodological requirements for knowledge generation (further compare Wahl 2006: 71; Schulze-Fielitz 2005: 63, 65 et seq.; Trute 2005: 87, 91 et seq.; 104 et seq.). The intensity of such an entanglement of scientific methodology and law can be illustrated by the market regulation of telecommunications, which in its sequence of market definition, market analysis and regulatory decisions transforms a variety of economic facts into legal acts (Broemel 2010a). Another example is the case of genetically modified organisms, as the conceptual knowledge about them is normatively influenced beforehand and thus pre-prepared by law (Trute 2005: 87, 100 et seq.). Examples are the REACH Regulation of the European Union ${ }^{10}$ and the complimentary regulation on test methods, ${ }^{11}$ where test methods, test arrangements, contextual conditions etc. are detailed on hundreds of pages of the Official Journal of the EU. In this way, a host of aspects that one would typically see as the genuine task of science are converted into legal elements. Similar processes can be observed with regard to related pharmaceutical issues. Unfortunately, often those very institutions responsible for causing risks also have to perform this kind of normatively guided knowledge generation - a very risky distribution of knowledge production, as they may not be unbiased producers. In a field like drug safety, one can observe the consequences such an approach might have, considering that impartial knowledge production is seldom at hand. Therefore, a complementary institutional structure needs to be established in order to assess the benefit of drugs and

10 Regulation (EC) No. 1907/2006 of the European Parliament and the Council of 18.12.2006 on Registration, evaluation, allowance and control of chemical substances (REACH), on the establishment of a European agency on Chemical Substances, amending Directive 1999/45/EC and nullifying Regulation (EEC) No. 793/93 of the Council, and of Regulation (EC) No. 1488/94 of the Commission, the Directive 76/769/EEC of the Council as well as Directives 91/155/EEC, 93/67/EEC, 93105/EC and 2000/21/EC of the Commission, OJ L 396 v. 30.12.2006, 1 (http://eur-lex.europa.eu/LexUriServ/LexUriServ.do?uri=CONSLEG:2006R1907:20121009:DE:PDF; 25.07.2019).

11 Regulation (EC) No. 440/2008 of the Commission of 30.05.2008 on the Establishment of proof methods according to Regulation (EC) No. 1907/2006 of the European Parliament and the Council on Registration, evaluation, allowance and control of chemical substances (REACH), OJ L v. 31.05.2008, 1 et seq. 
the knowledge produced about them. However, complaints of a biased knowledge generation in this field remain endemic after all.

\subsubsection{Institutionalization of a Knowledge Generating Infrastructure}

Another instrument is the institutionalisation of an infrastructure specifically designed for a kind of permanent knowledge production in important fields. Such institutions are the currently emerging European networks with specialised European agencies as central knots in a network of national agencies. A couple of commonly cited but not thoroughly researched institutions are the European Food Safety Agency $(\mathrm{EFSA})^{\mathbf{1 2}}$ and the network of the European statistics authorities (ESS), which is less integrated than the EFSA network, and the European Union Agency for Network and Information Security (ENISA), to mention just a few. In the field of prevention and surveillance concerning epidemics, the European Centre for Disease Prevention and Control (ECDC), a specialised European agency, ${ }^{13}$ has to be mentioned. This agency is part of an international surveillance network coordinated by the WHO in the event of contagious diseases, in particular those that may lead to pandemics. This network is not only responsible for observing possible outbreaks worldwide and collecting necessary data, but also for analysing and evaluating the situation. This system works on the basis of generally applicable standards and procedures. In this respect, international law institutionalises this network, creates obligations for the Member States to collect and disseminate data, and establishes sufficient scientific resources for the necessary production of knowledge, which is, ultimately again, based on common standards (for a detailed analysis see Trute 2018). Moreover, possible interventions and necessary instruments are standardised and evaluated so that the entire framework is subject of an evaluation.

EFSA, the food safety agency, for instance, is the focal point of a network of national expert institutions. The knots of the EFSA-Network are not just responsible for determining and assessing risk in one specific case, but they observe the entire field of health risks and generate knowledge in a more generic way, which allows national agencies to draw upon that knowledge. In fact, the national expert institutions themselves act in a continuous scientific, consulting manner for the European Commission, the Member States, the European Parliament and the general public and

12 It is a task of the respective authorities, according to $\S 22$ II Reg. (EC) 178/2002, to offer scientific advice as well as scientific and technical support for the adoption of laws and policies of the Community in all areas, which directly or indirectly have consequences for the security of foods and nutritional substances. It is supposed to make available independent information in relation to all questions on this topic and advice on risks at all times.

13 Decision No. 1082/2013/EU of the European Parliament and of the Council of 22.10.2013 on serious cross-border threats to health and repealing Decision No. 2119/98/EC, OJ L 293, 05.11.2013; for an overview on the matter refer to Trute 2015: 87 et seq. 
in this way generate knowledge extending beyond one specific case. Member States designate functions and positions on a national level to support EFSA, ${ }^{14}$ and accordingly coordinate their respective network on the national level. Thanks to this institutional design, the EFSA-Network has at its disposal a net of mutual peer reviews through the different member states, agencies and their experts, which could hardly be institutionalised in a national context due to the lack of sufficient experts. This transnational set-up also allows the production of risk knowledge that is distanced from national application contexts, and that can be used as a basis in national regulatory contexts. This entire procedure naturally involves standardisation and harmonisation of knowledge.

To sum up: knowledge generating infrastructures represent a new order of producing and stabilising knowledge. The strategy is different from the classical model insofar as it represents no longer a hierarchical knowledge production with full responsibility of the state, but a heterarchical knowledge production (often) with a decisive function of non-state actors; legal knowledge production is shaped by law in varying degrees of intensity, and the generation of knowledge is no longer based on the normal procedure of the discipline. Through the creation of knowledge infrastructures in the form of networks, a kind of permanent peer review between different actors and agencies with different cultural and national backgrounds is institutionalised.

\section{Harmonization by Setting a Frame for a Common Practice in the EU}

If it is true that the law and its application are grounded in shared conventions and meanings they are challenged in the processes of Europeanisation and internationalisation of law. It is a truism that a common understanding of rules does not come naturally. Despite sharing a common language, the evolution of the federal state in Germany, just like other federal states, has been faced with the problem of a consistent understanding of federal rules. They are always perceived against the background of cultural habits, administrative cultures and specific interests. A harmonised understanding is even more complicated in the case of a culturally diverse context like the European Union or in the case of a worldwide cooperation. Due to technological path dependencies, regulatory and legal traditions as well as experiences with problemsolving, and interests in certain solutions, a common frame of problem perception has to be produced. The networks described before may overcome cultural differences

14 Refer also to EFSA, Decision concerning the establishment and operation of European Networks of scientific organizations operating in the fields within the Authority's mission, https://www.efsa. europa.eu/sites/default/files/assets/panelnetworksrop.pdf; 25.07.2019). 
in different member states by constituting a forum for discussion about how to perceive and solve problems. As a result, the European networks establish a kind of harmonised European knowledge basis as foundation for the administrative handling of affairs also by Member State authorities.

The inconsistent perception of problems is only one example of the general problem of a Europeanised and internationalised administration. An additional crucial aspect is constituted by the plurality of national administrations in Europe in the context of various cultures and the knowledge bases that are associated with them. For European administrative law, integration in a unified European Administration Area is a necessary characteristic. Despite this integration, European Administration has to deal with particular administrative cultures and the knowledge bases they are embedded in. If a more or less unified administration of the European internal market is to be achieved, then administrative cultures need to be harmonised with regard to relevant internal-market-associated issues, so that mutual trust in the handling of affairs from all sides can be expected. This shifts the issue of knowledge to a new level.

To address these problems, an administration founded on European cooperation in varying degrees of intensity can do no more than, first and foremost, to build up information networks - and to structure them in such a way that the intensity of cooperation is concomitant with the extension of the recognition the respective decisions will receive in different national contexts. This does not only imply that the already existing stocks of knowledge have to be made accessible to others in the interest of administrative efficiency. Rather, analysis can run considerably deeper precisely on these points, as these information networks do not just aim at efficiency, but rather at the construction of a shared perspective on issues, and ultimately at the construction of a shared reality model concerning issues of administration and problem solution (with regard to the example of the European Research Area see more in Pilniok 2011). In order to reach this vision, however, much more than just the publication of information about a case in question is necessary; rather, it is essential to provide access to the actual administrative practice, to distribute files and work on it, so that a common reference to a newly constructed common practice can follow suit. As knowledge of the administration is constructed through law but also through the way it is applied across time and through various instruments, the application is bound also to implicit knowledge, administrative cultures and ways of doing things (Augsberg 2014: 27; Trute 2010: 11 et seq). This can still be observed across a federal state, and it demonstrates the constitutive importance of explicit and implicit cognitive preconditions for the application of law. With this in mind, the role of law is all the more complex as it does not just fundamentally depend on these preconditions, but it also itself contributes to the establishment of this cognitive structure. An essential part of regulations of the European as well as international law is dedicated to generating these cognitive structures. This process does not only refer to informational relationships. It rather refers to what in research about governance would be termed framing: the formation 
of a common perspective that is grounded on a shared knowledge following a more or less common practice.

\section{A New Order of Knowledge: Digitisation and its Consequences}

Up to this point we have described the development of different orders of knowledge and their significance for the law and vice versa. We shall now turn to changes of these orders of knowledge as a result of digitisation. Two social areas affected to a large extent - and therefore perceived as especially problematic areas - are labour environment and production processes. But these changes are of a 'normal' order and the law will cope with them more or less efficiently and quickly. I also do not share the fear of some legal professionals, especially lawyers, that hordes of well-trained and cheap robots will replace them and thereby threaten well-established business models (keyword 'legal techs'). Nor am I entertaining the visionary dream - or nightmare - of the 1970s that at the end of the digital revolution perfect automations capable of subsuming facts under norms will take over judicial functions. Some of these developments may have desirable aspects, but they are discussed without the necessary differentiation, and seldom with a deeper reflection on the consequences for the law itself. A more reflexive approach might start with the question: What is changing for law and its practice by digitisation, understood here as combination of big data sets, artificial intelligence and generated knowledge? And more precisely in our context: What changes must be expected in terms of knowledge generation by processes of digitisation?

\subsection{Changes in the System of Publication}

Digitisation changes the system of publication within the legal system. Although remarkable changes have already occurred with the use of big databases in the last two decades, these developments are seldom analysed with respect to the practice of law, in particular not with regard to the way knowledge is created. It seems to be a truism that non-digitised literature will lose its importance. The transaction costs are reduced enormously if the media are digitised and accessible in electronic formats and databases. Additionally, the possibility of random findings, which increase the variation possibilities, decreases. This is a common observation in students' qualification papers, and it does not take prophetic abilities to predict that lawyers socialised in this way will orient their future practice towards digitalised research. Publishers are already aligning themselves to this state of affairs anyway. Moreover, the hierarchy of reputation and the function of some book genres like the important cate- 
gory of commentaries will change, and this will change the way legal knowledge is distributed and stabilised. Online commentaries, accessible via publishing houses, prefer a kind of amorphous commentary, with every new decision added speedily, yet at the expense of a more systematic analysis, which would take time.

As a consequence of the fact that all more or less important decisions of courts, from the District Court of Berlin Charlottenburg to the Federal Constitutional Court or the Court of Justice of the EU, can be easily accessed for research, they are increasingly referred to indiscriminately as a resource for argumentation without embedding them systematically, and they are attributed equal importance without any reflection of quality. In this way, they are turning into a quarry for any legal argumentation. The knowledge produced in this manner will consequently be more fragmented. This development may appear like a minor change for the time being, but it will have important implications for the way knowledge is generated and stabilised within the legal realm in the long run. Indeed, the traditional, more or less hierarchical order of systematised and evaluated knowledge might vanish gradually. Compared with the USA, where similar developments are taking place, little reflection is found in Germany about these issues.

\subsection{Corpus Linguistics}

A problem all legal systems share is the assignment of meanings to legal texts, legal norms, or previous decisions. This can be done intuitively, through the use of dictionaries or, more recently, by taking recourse to corpus linguistics (Vogel/Hamann/ Gauer 2018). This procedure promises an analysis of the use of keywords in different texts, text genres, and at different occasions, and thus an 'objectification' of language use. It is therefore in principle compatible with the above-mentioned methodological positions focused on textual exegesis. In any case, this new tool allows access to any number of texts and the way they handle problems of meaning.

Corpus linguistics in law has long since left the purely academic field, and in some countries has become an instrument of analysis of legal usage. Particularly in the USA, the general use of linguistic corpora analyses in relation to legal texts is so far advanced that it is now accepted even in court decisions and thus replaces the quasi-intuitive assignment of meaning with a reference to the previous use of language, which is derived from a decipherment of "ordinary language" (for an overview see Solan/Gales 2017). Although the function of ordinary language in the US legal system might be different from that in Continental European systems, one has to keep in mind that these techniques are not limited to deciphering ordinary language. The use of corpus linguistics no doubt will also trigger a new kind of knowledge production. Whether or not the use of these tools will broaden or reduce the scope of varieties, restricting usages to examples from the past is highly problematic. However, presently the technique is limited to the area of research, and therefore has not yet 
had any noteworthy impact on legal knowledge compared to the traditional procedures of the discipline.

Of course, there are limits of the corpus linguistic approach. It cannot automate adjudication like a real automat and contribute automatically to the relevant corpus of knowledge for the application of law (Vogel/Hamann/Gauer 2018). Attempts of the 1970s in this direction failed (Rave/Brinkmann/Grimmer 1971), and recent efforts of modelling automatic judicial decision-making display a very simplistic model of minor relevance for the processes of judicial decision-making. The model is too simple in terms of language theory as well as regarding the reconstructions of application procedures, and it has therefore long been subject to considerable criticism from very different theoretical perspectives (for an extensive debate cf. Rübben 2015). A central drawback is that it is based on a model of legal knowledge that refers to meaning as being inscribed into the text of the law. This fosters the idea of the possibility of a simple formalisation of legal language. Essentially, however, the attribution of meaning to legal texts is the result of social practice. In complex application contexts with little stable knowledge of a legal and extra-legal nature, or in dynamic situations, a simple legal application model reaches its limits. Whether these limits will be overcome by advanced technologies of machine learning is still an open question. At least for the time being, there are good arguments that one cannot replace the cognitive processes by algorithmised knowledge generation and decision-making, as they necessitate complex processes of contextualisation, including sensory input and background knowledge (Vogel/Hamann/Gauer 2018).

\subsection{Prediction Technologies and Profiling}

Similar problems might arise for other technologies currently in use in the surveillance sector, which will generate completely different structures of knowledge from the perspective of the legal system, for example in other Big Data technologies like risk clustering in the field of application for loans or insurances. Profiling in this context elucidates the ensuing problems to a certain extent, insofar as the individual here is no longer treated as an individual, but as a member of a risk class. Knowledge production through Big Data technology detects patterns, and an individual is considered as part of the pattern if they fit the pattern's criteria (Broemel/Trute 2016). This procedure is a matter of exclusively statistical knowledge that ignores additional information about individuals, as well as the individuals' own claims regarding their personality and their situation. The problem here is not the much debated issue of a transparent customer, whose secrets are disclosed, as is often criticised regarding individual privacy. The problem here lies in the fact that a centralised set of knowledge about an individual is generated on the basis of the individual's digital tracks and those of millions of other people, and that this knowledge is used to make claims about specific individuals in society. This procedure reduces their options for self- 
determination and identity. With this strategy, it does not matter whether the knowledge is representative of the individual, nor whether the information is true. The very suggestion of truth reduces individual options and thus devalues the concepts of self-determination and identity. The constructivist basis of this type of knowledge is covered up by the validity claims of its mathematical methodology, and an illusion of objectivity is created.

\subsection{The Validation Problem}

The principle of the rule of law requires that any claim to knowledge, including the knowledge that legal decisions are based upon, can be reviewed - at least in principle. The knowledge that is used as the basis for regulatory decisions should meet certain quality standards; it should in principle be verifiable, revisable and thus always contestable in legal proceedings. However, forms of subsequent re-evaluation reach their limits where forms of algorithmic knowledge generation from large data stocks (often collected over a long period of time) are concerned, for example in the police and secret service sector. The algorithmically generated knowledge tends to be opaque regarding the process of its genesis. This is all the more true if the routines of the programme are not accessible to the users. Even if the software is accessible, in selflearning systems or in more complex fields of application, it becomes difficult or even impossible to retrace and reproduce the genesis of the results. If this scenario should come true, the judicial scrutiny, which is of limited effect anyway in areas like the ones mentioned, will be limited even further. In Germany, people often take comfort in the idea that stricter data protection requirements will ensure individual control over a knowledge base related to them. However, the data protection approach, which is not entirely free of fictional elements, displays limited efficacy in constellations like the ones outlined above. Moreover, individual rights related to personal data might make the knowledge base even more biased than before, because the use of veto rights will exclude some of the data. This option will therefore be of limited help. A possible solution might lie in the development of explainable artificial intelligence. So far, however, there are no examples of such systems in the legal system. Therefore, with a view to the knowledge base of legal decisions it is necessary to look for additional measures and instruments to assure basic standards of decision-making according to the rule of law, if more possibilities of algorithmic knowledge generation should be implemented in legal knowledge production. 


\section{References}

Albers, M. (2008). Die Komplexität verfassungsrechtlicher Vorgaben für das Wissen der Verwaltung: Zugleich ein Beitrag zur Systembildung im Verwaltungsrecht. In: I. Spieker [Döhmann] and P. Collin. Eds. Generierung und Transfer staatlichen Wissens im System des Verwaltungsrechts. Tübingen: Mohr Siebeck, 50-71.

Augsberg, I. (2014). Informationsverwaltungsrecht. Tübingen: Mohr Siebeck.

Broemel, R. (2010a). Strategisches Verhalten in der Regulierung. Tübingen: Mohr Siebeck.

Broemel, R. (2010b). Wissensdistribution im Zivilrecht: Vorvertragliche Aufklärungs- und Informationspflichten. In: H. Ch. Röhl. Ed. Wissen: Zur kognitiven Dimension des Rechts (Die Verwaltung - Beiheft 9). Berlin: Duncker \& Humblot, 89-110.

Broemel, R. (2013). Compliance durch Wissen. Rechtswissenschaft 1, 62-90 [DOI: 10.5771/18688098-2013-1-62].

Broemel, R. and H.-H. Trute (2016). Alles nur Datenschutz? Zur rechtlichen Regulierung algorithmenbasierter Wissensgenerierung. Berliner Debatte Initial 27(4), 50-65.

Busse, D. (1993). Juristische Semantik: Grundfragen einer juristischen Interpretationstheorie in sprachwissenschaftlicher Sicht. Berlin: Ducker \& Humblot.

Canaris, C.-W. and K. Larenz (2001). Methodenlehre der Rechtswissenschaft. Berlin, Heidelberg: Springer.

Christensen, R. J. (1989). Was heißt Gesetzesbindung? Eine rechtslinguistische Untersuchung. Berlin: Duncker \& Humblot.

Fassbender, B. (2006). Wissen als Grundlage staatlichen Handels. In: J. Isensee and P. Kirchhof. Eds. Handbuch des Staatsrechts der Bundesrepublik Deutschland, vol. IV. Heidelberg: C. F. Müller, 243-312.

Fish, S. (1989). Working on the Chain Gang: Interpretation in Law and Literature. In: idem. Ed. Doing What Comes Naturally. Durham, London: Duke, 87-102.

Fish, S. (2011). Gibt es einen Text in diesem Kurs. In: idem. Ed. Das Recht möchte formal sein. Frankfurt/Main: Suhrkamp, 35-52 [resp. Fish (1980). Is there a Text in this Class. In: idem. Ed. Is there a Text in this Class? Cambridge, London: Harvard University Press, 303, 308-310].

Harenburg, J. and G. Seeliger (1979). Transformationsprozesse in der Rechtspraxis: Eine Untersuchung von Rechtsanwalt/Klienten-Gesprächen. In: G. Böhme and M. v. Engelhardt. Eds. Entfremdete Wissenschaft. Frankfurt/Main: Suhrkamp, 56-86.

Herzmann, K. (2010). Konsultationen. Tübingen: Mohr Siebeck.

Kästle-Lamparter, D. (2016). Welt der Kommentare. Tübingen: Mohr Siebeck.

Ladeur, K.-H. (1995). Das Umweltrecht der Wissensgesellschaft. Berlin: Duncker \& Humblot.

Ladeur, K.-H. (2016). Recht - Wissen - Kultur: Die fragmentierte Ordnung. Berlin: Duncker \& Humblot.

Lee, K. I. (2010). Die Struktur juristischer Entscheidungen aus konstruktivistischer Sicht. Tübingen: Mohr Siebeck.

Müller, F., R. Christensen, and M. Sokolowski (1997). Rechtstext und Textarbeit. Berlin: Duncker \& Humblot.

Müller, F. and R. Christensen (2004). Grundlegung für die Arbeitsmethoden der Rechtspraxis (Juristische Methodik 1). Berlin: Duncker \& Humblot.

Oeter, S. (2011). The Openess of International Organisations for Transnational Public Rule-Making. In: O. Dilling, M. Herberg, and G. Winter. Eds. Transnational Administrative Rule-Making. Oxford: Hart Publishing, 235-252.

Ogorek, R. (2011). Inconsistencies and Consistencies in the $19^{\text {th }}$ Century Legal Theory. German Law Journal 12(1), 34-57. 
Pilniok, A. (2011). Governance im europäischen Forschungsförderverbundes. Tübingen: Mohr Siebeck.

Rave, D., H. Brinkmann, and K. Grimmer (1971). Paraphrasen Juristischer Texte. Darmstadt: Deutsches Rechenzentrum.

Reiling, K. (2016). Der Hybride: Administrative Wissensorganisation im privaten Bereich. Tübingen: Mohr Siebeck.

Röhl, H. Ch. (2012). § 30 Ausgewählte Verwaltungsverfahren. In: W. Hoffmann-Riem, E. Schmidt-Aßmann, and A. Voßkuhle. Eds. Informationsordnung, Verwaltungsverfahren, Handlungsformen (Grundlagen des Verwaltungsrechts 2). $2^{\text {nd }}$ ed., Tübingen: Mohr Siebeck, 752-759.

Rosen, L. (2006). Law as Culture. Princeton/NJ: Princeton University Press.

Rübben, S. (2015). Bedeutungskampf: Zur Kritik der zeitgenössischen Rechtstheorie. Weilerswist: Velbrück.

Schulze-Fielitz, H. (2005). Responses of the Legal Order to the Loss of Trust in Science. In: H. Nowotny et al. Eds. The Public Nature of Science under Assault. Heidelberg, Berlin: Springer, 63-86 [DOI: 10.1007/3-540-28886-4_4].

Smits, J. M. (2017). What is Legal Doctrine? On Aims and Methods of Legal-Dogmatic Research. In: R. v. Gestel, H.-W. Micklitz, and E. L. Rubin. Eds. Rethinking Legal Scholarship. Cambridge: Cambridge University Press, 207-228 [DOI: 10.1017/9781316442906.006].

Solan, L. M. and T. Gales (2017). Corpus Linguistics as a Tool in Legal Interpretation. Brigham Young University Law Review 6, 1311-1357.

Somek, A. (2006). Rechtliches Wissen. Frankfurt/Main: Suhrkamp.

Somek, A. (2011). The Spirit of Legal Positivism. German Law Journal 12(2), 729-756.

Stegmaier, P. (2009). Wissen, was Recht ist: Richterliche Rechtspraxis aus wissenssoziologischer Sicht. Wiesbaden: Springer.

Trute, H.-H. (2005). Democratizing Science: Expertise and Participation in Administrative Decision-Making. In: H. Nowotny et al. Eds. The Public Nature of Science under Assault. Heidelberg, Berlin: Springer, 87-108 [DOI: 10.1007/3-540-28886-4_5].

Trute, H.-H. (2010). Wissen: Einleitende Bemerkungen. In: H. Ch. Röhl. Ed. Wissen: Zur kognitiven Dimension des Rechts (Die Verwaltung - Beiheft 9). Berlin: Duncker \& Humblot, 11-38.

Trute, H.-H. (2015). How to Deal with Pandemics. In: T. Eger, S. Oeter, and S. Voigt. Eds. International Law and the Rule of Law under Extreme Conditions: An Economic Perspective. Tübingen: Mohr Siebeck, 115-160.

Trute, H.-H. (2016). Law and Knowledge: Remarks on a Debate in German Legal Science. Ewha Journal of Social Sciences 32(2), 5-38.

Trute, H.-H. (2018). Pandemien als potentiell globale Katastrophe. Zeitschrift für das Gesamte Sicherheitsrecht 4, 125-132.

Valverde, M. (2009). Law's Dream of a Common Knowledge. Princeton/NJ: Princeton University Press.

Vogel, F., H. Hamann, and I. Gauer (2018). Computer-Assisted Legal Linguistics: Corpus Analysis as a New Tool for Legal Studies. Law \& Social Inquiry 4, 1340-1363.

Voßkuhle, A. (2008). Expertise und Verwaltung. In: H.-H. Trute et al. Eds. Allgemeines Verwaltungsrecht: Zur Tragfähigkeit eines Konzepts. Tübingen: Mohr Siebeck, 637-664.

Wahl, R. (2006). Herausforderungen und Antworten: Das Öffentliche Recht der letzten fünf Jahrzehnte. Berlin: de Gruyter.

Wollenschläger, B. (2009). Wissensgenerierung im Verfahren. Tübingen: Mohr Siebeck. 